\title{
Bioplastics disposal: how to manage it
}

\author{
F. Gironi \& V. Piemonte \\ University of Rome "Sapienza" Department of Chemical Engineering \\ Materials \& Environment, Italy
}

\begin{abstract}
The biodegradable plastics were introduced in the 1980s in order to detect possible renewable feedstock to produce non petroleum-based plastics, as well as to reduce the environmental burdens due to the landfill volume increase. To this end, in the last years different typologies of bioplastics like PHB, PCL, Mater-Bi and PLA were introduced.

In order to verify the benefits of bioplastics in comparison to conventional plastics it is necessary to evaluate the environmental impact derived from production, utilization and disposal of the two kinds of material. Nowadays, the most important tool to evaluate the environmental impact of a material (for example bio or conventional plastics) is the life cycle assessment (LCA) that determines the overall impact of a plastic on the environment by defining and analysing several impact indices. In particular, global warming, human toxicity, abiotic depletion, eutrophication, acidification and many other impact indices directly related to the production, utilization and disposal of the plastics studied in this work are considered.

In this paper an analysis of the different disposal scenarios (in particular composting and recycling processes) applied to the most important bioplastics currently on the market (PLA made from Nature Works and Mater-Bi made from Novamont), was carried out by using the LCA methodology and by also taking into account the Land Use Change (LUC) emissions. Cost and benefits of the bioplastic disposal were also compared to these of the conventional plastics.
\end{abstract}

Keywords: bioplastics, waste management, Land Use Change, LCA, recycling. 


\section{Introduction}

The application of biomass like starch, cellulose, wood and sugar used to substitute fossil resources for the production of plastics, is a widely accepted strategy towards sustainable development.

The worldwide production of bioplastics in 2008 was about 350,000 tons/year and is very modest when compared with 200 million tons/year of conventional plastics derived from petroleum; it is estimated that in the near future, the growth will be exponential, reaching about 900,000 tons/year in 2010 (Widdecke et al. [1]). The major manufacturers are Nature Works (with a production of 140,000 tons/year of PLA (Tokiwa and Calabia [2]) and Novamont (with a production of 35,000 ton/year of Mater-bi, MB, starch-based Bioplastic (Bastioli [3])).

The interest in the development of biodegradable plastics noticed in recent years, is due to reasons of both environmental and strategic nature (Zhang et al. [4]; Demirbas [5]; Anderson et al. [6]; Gross and Kalra [7]). As a matter of fact, in order to reduce the environmental impact of plastics (especially in terms of $\mathrm{CO} 2$ released in the environment) some of the products obtained from agriculture (starch, cellulose, wood, sugar) are used as raw materials. This way the net balance of carbon dioxide is reduced since growing bioplastic feedstocks remove carbon dioxide from the atmosphere. Furthermore, petroleum, with a constantly rising price, is replaced by renewable raw materials obtained from agriculture.

Most life-cycle studies have found that replacing petroleum-based plastics with bioplastics made from renewable feedstocks, such as corn, reduces greenhouse gases (GHGs) (Harding et al. [8], Krueger et al. [9], Patel [10]), but these analysis have failed to count the carbon emissions that occur as farmers worldwide convert forest and grassland to new cropland to replace the corn diverted to bioplastics. In fact, to produce bioplastics, farmers can directly plow up more forest or grassland, which releases to the atmosphere much of the carbon previously stored in plants and soils through decomposition or fire. The loss of maturing forests and grasslands also foregoes ongoing carbon sequestration as plants grow each year, and this foregone sequestration is the equivalent of additional emissions. Therefore, by excluding emissions from landuse change, most previous accountings were one-sided because they counted the carbon benefits of using land for bioplastics but not the carbon costs, the carbon storage and sequestration sacrificed by diverting land from its existing uses (Searchinger et al. [11], Righelato and Spracklen [12], Plevin and Mueller [13]). Searchinger et al. [11] and Righelato and Spracklen [12] in their studies dealing with the land use change emissions associated to biofuels production from renewable sources, highlighted that, for example, corn-based ethanol, instead of producing a $20 \%$ savings, nearly doubles greenhouse emissions over 30 years and increases greenhouse gases for 167 years. This finding about the biofuels point out the value of using agricultural or food waste products as feedstock for the corn-based ethanol production in order to reduce the LUC emissions.

The aim of this paper is to demonstrate that the same results found by Searchinger et al. and Righelato and Spracklen about the biofuels can be 
considered valid for the bioplastics behaviour, but in this case a smart management of the bioplastic wastes could represent a good alternative to the agricultural waste utilization. To this end a Life Cycle Assessment (LCA) cradle to grave of the most important bioplastics currently on the market (polylactic acid, PLA, made from Nature Works and Mater-Bi made from Novamont), was carried out. Furthermore, the LCA results obtained for the bioplastics were compared to these obtained for some representative petroleum-based plastics, such as polyethylene (PE) and polyethylene terephthalate (PET), in order to assess, from an environmental point of view, the bioplastics reliability.

\section{Methodology}

The functional units of the LCA studies are 3 billion of PLA bottles of 1.5 litres (that is 84000 metric tons of PLA) and 3.25 trillion of shoppers made from Mater-Bi (that is 78000 metric tons of Mater-Bi). These functional units are chosen in order to consider as possible scenario the replacement of $20 \%$ of PET bottles production in Italy and the $20 \%$ of PE shoppers production in the same country, with PLA bottles and Mater-Bi shoppers, respectively. It is worth noting that a same mass was assumed for the PLA and PET bottles (28 $\mathrm{g}$ for each bottle), while a different mass was considered for the PE and Mater-Bi shoppers due to their different mechanical properties. In particular masses of 24 and $16 \mathrm{~g}$ were assumed for shoppers made from Mater-Bi and PE, respectively.

The LCA studies were carried out by using the "SimaPro7" LCA software that implement several LCA methodologies. In particular, it was used the Intergovernmental Panel on Climate Change (IPCC) for the assessment of the Global Warming (Levenmore [14]) and the Eco-indicator 99 methodology that implements a "Damage Oriented Approach" (Goedkoop et al. [15]. This method accounts for 11 impact categories (mid point level): Carcinogens, Respiratory Organics, Respiratory Inorganics, Climate Change, Radiation, Ozone Layer, Ecotoxicity, Acidification/Eutrophication, Land Use, Minerals and Fossil Fuels. The first six impact categories are then normalized and grouped in the macrocategory (end-point level) "Human Health" that considers the overall impact of the emissions associated to the product analysed on the human health. The categories Ecotoxicity, Acidification/Eutrophication and Land Use are included in the macro-category "Ecosystem Quality" that accounts for the overall environmental damage, while the "Minerals and Fossil Fuels" are grouped in the macro-category "Resources" that considers the depletion of non renewable resources.

For the development of the life cycle inventories (LCI) it was used, both for petroleum-based plastics and bioplastics, data included in the Ecoinvent v.2.0 database [16]. This database includes information on production of energy (from oil, natural gas, coal, lignite, nuclear, hydroelectric, photovoltaic, wind and biofuels), extraction and processing of raw materials, transport, production processes and auxiliary. The data relate to international scenarios, which cover the entire industrialized world. In particular, the PET and PE data are based on the Eco-profiles of the European plastics industry (24 European production 
sites); while, as reported by the Ecoinvent database, the data concerning PLA are obtained from data published by Nature Works on the PLA6 (Erwin et al. [17]) by replacing the Renewable Energy Certificates, RECs, (used in the PLA production plant located in Nebraska (US) to replace the $100 \%$ of electricity consumption [17]), with energy taken from grid electricity (European Country mix) produced by non-renewable resources [16]. On the same way, Mater-Bi inventory is based on calculations and extrapolations (reported in the Ecoinvent Report $\mathrm{n}^{\circ} 21$ [20]) using highly aggregated background data from the environmental product declaration of Mater-Bi (Novamont, 2004, Italy) [22].

As for LUC considerations, the method proposed by Searchinger et al. [11] was followed. In particular, since greenhouse emissions depend on the type of lands converted, new cropland was assigned in each region to different types of forest, savannah, or grassland on the basis of the proportion of each ecosystem converted to cultivation in the 1990 s and assumed that conversion emits $25 \%$ of the carbon in soils (Guo et al. [18], Murty et al. [19]) and all carbon in plants, which must be cleared for cultivation. For mature forests in carbon equilibrium, it was only calculated emissions from the initial conversion. For growing forests, we attributed emissions to bioplastics equal to the amount of carbon those forests would have been sequestered over 30 years, if they were not cut (Searchinger et al. [11]).

\section{LCAs cradle to gate and LUC emissions}

In order to assess the reduction of GHGs achievable by displacing the $20 \%$ of PET bottles and PE shoppers production in Italy with PLA bottles and Mater-Bi shoppers, respectively, LCA studies cradle to gate were carried out by using the IPCC method. A general simplified process flow diagram is given in figure 1, including an indication of the system boundaries for the packaging systems studied. As it can be seen from the flow chart the system boundaries comprise:

- the polymer production, starting from crude oil extraction for the PET and PE and crop farming for PLA and Mater-Bi up to the final polymer;

- the transportation of polymers to the bottles/shoppers production plants. The transportation of PLA/MB and PET/PE pellets for subsequent processing in the finished product was carried out by rail. The transportation distance was assumed equal to $100 \mathrm{~km}$. The environmental burden was calculated by taking into account the tons carried per kilometer (tkm);

- the injection moulding and blow stretching of the final bottles (bottle production processes);

- the blow foil extrusion of the final shoppers (shopper production processes)

Not included within the system boundaries are the retail of bottles and shoppers; production and transport of secondary and tertiary packaging; production and disposal of the infrastructure (machines, transport media, roads etc) and their maintenance. Nature is not part of the system boundary, this 


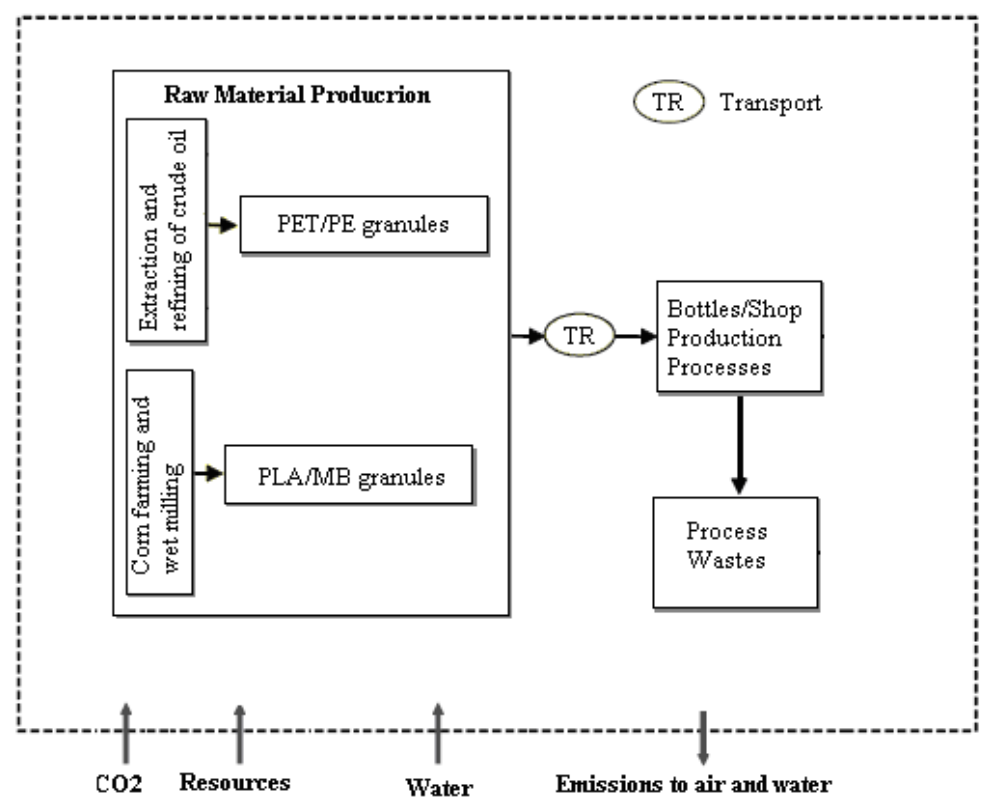

Figure 1: System boundaries applied in this study.

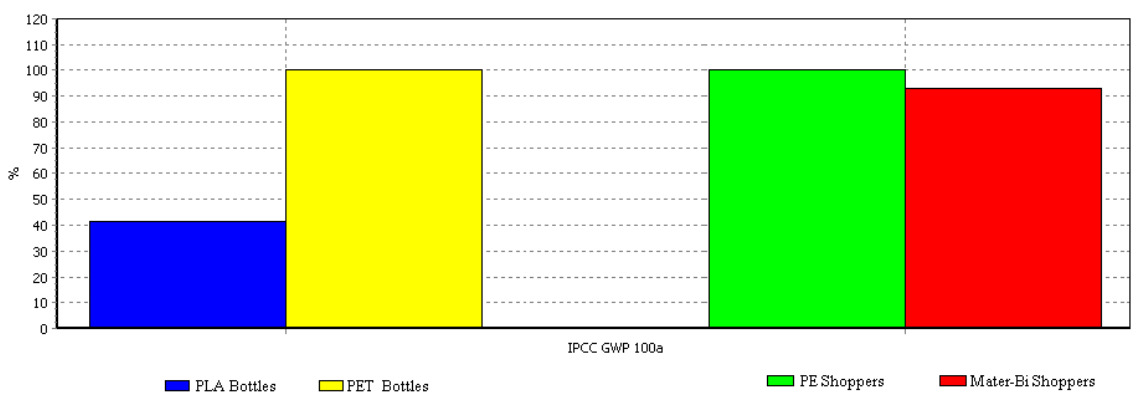

Figure 2: Global Warming Potential of PET/PLA bottles and PE/MB shoppers assessed by IPCC method.

implies that all the emissions (fertilizers, pesticides etc.) relative to the area allocated for agricultural production are strictly taken into account.

The results reported in figure 2, in terms of Global Warming Potential, GWP, (measured as $\mathrm{kg}$ of $\mathrm{CO} 2$ equivalents), clearly show the GHGs saving achievable by displacing the petroleum-based plastics with the bioplastics. In particular, the PLA saves for the $60 \%$ (that is 164000 metric tons CO2eq/year) and the Mater$\mathrm{Bi}$ for the $10 \%$ (that is 9000 metric tons $\mathrm{CO} 2 \mathrm{eq} / \mathrm{year}$ ). It is worth noting that in this study we referred to a Mater-Bi obtained by co-polymerization of petroleumbased plasticizers (66\%) and thermoplastic starch (TPS) obtained from corn (34\%) (Werner and Stettler [20]). 
In order to account for the Land Use Change (LUC) emissions, it was considered that for the production of $1 \mathrm{~kg}$ of PLA granules, $1.56 \mathrm{~kg}$ of corn are needed (Erwin et al. [17]), while $0.334 \mathrm{~kg}$ of corn are needed for the production of $1 \mathrm{~kg}$ of Mater-Bi [20]. Therefore, since the production of $1 \mathrm{~kg}$ of corn requires $1.7 \mathrm{~m}^{2}$ of arable land [17], the displacing of $20 \%$ of the production in Italy of PET bottles and PE shoppers requires 22276.8 hectares for the PLA and 4773.6 hectares for the Mater-Bi. Searchinger et al. [11] in their work report an emission value of 351 metric tons of $\mathrm{CO} 2 \mathrm{eq}$ per hectares of land converted to cropland, while Righelato and Spracklen [12] report an emission value of 305 metric tons of $\mathrm{CO} 2$ eq per hectares of converted land. In this study it was assumed an average value of 328 metric tons of CO2eq emitted for the land conversion. This way, the GHG savings from PLA would equalize and therefore pay-back carbon emissions from land use change in about 44.5 years, while 174 years are needed to balance the GHG emissions derived from Mater-Bi using, meaning GHGs increase until the end of that period for both PLA and Mater-Bi. In sake of the clarity, a new type of Mater-Bi is currently under development in order to increase up to $100 \%$ the renewable feedstock fraction. Therefore, the considerations on Mater-Bi products should be reformulated when a new LCI on this product will be available.

\section{Waste Management - LCA cradle to grave}

The accounting for the land use change emissions put under discussion the reliability of bioplastics for the displacement of petroleum-based plastics, at least from an environmental point of view.

The use of agricultural waste products finalized to the production of bioplastics is a valid solution to the problem, that, anyway, could be further solved if a smart management of the bioplastic wastes is carried out.

Indeed, in order to reduce up to zero the LUC emissions, raw materials that do not require land use for their production, such as renewable waste materials, should be used as feedstock for the bioplastics production. From this point of view, it is clear that the incineration or the landfilling of the bioplastic products are not valid alternative for a real solution of the problem; on the contrary the recycling could be a smart waste management option towards a drastic reduction of the environmental impact of the bioplastics.

In this paper, two recycling options were considered: the first one accounts for the composting of bioplastic products (in this case PLA bottles and MB shoppers), while the second one analyses the mechanical recycling of PET/PLA bottles and PE/MB shoppers. Since food-grade applications require that the recycled PET (R-PET) is free of contaminants which could migrate into the food stuff, recovered PET flakes have to undergo a combined vacuum and heat treatment. This was also considered in the R-PET recycling process modelling $[9,16]$. On the contrary, the R-PE recycling process do not account for vacuum and heat treatment because shoppers are not directly in contact with food. Since there are no available literature data on the PLA and MB recycling processes, the same models used for R-PET and R-PE were used also in this case. 
Figure 3 reports the results obtained by LCAs cradle to grave (in terms of Global Warming Potential) for PET/PLA bottles and PE/MB shoppers, accounting for waste scenarios considered in this work. It is evident from the figure that the bioplastic composting process is ineffective to the GHGs reduction if compared with the mechanical recycling process. From one hand, the composting process do not avoid the use of land for the agricultural raw material production (LUC emissions must be still taken in to account); on the other hand, the PLA composting shows a GHGs increase of 38\% in comparison to R-PLA and, on the same way, the Mater-Bi composting leads to GHGs increase of $41 \%$ with respect to R-MB. The above considerations lead to a first important conclusion: the recycling process, i.e. replacing virgin material with recycled polymer, is the only truly effective way for waste management to overcome the LUC problem. Anyway, it is clear that waste agricultural materials are still needed to start-up the bottle or shopper production processes.

Figure 3 also highlights that R-PLA leads to a real GHGs reduction of $8 \%$ respect to R-PET, while R-MB is characterized by GHGs increase of $19 \%$ respect to R-PE. This finding is mainly due to the overweight $(50 \%)$ of $\mathrm{MB}$ shoppers with respect to PE shoppers.

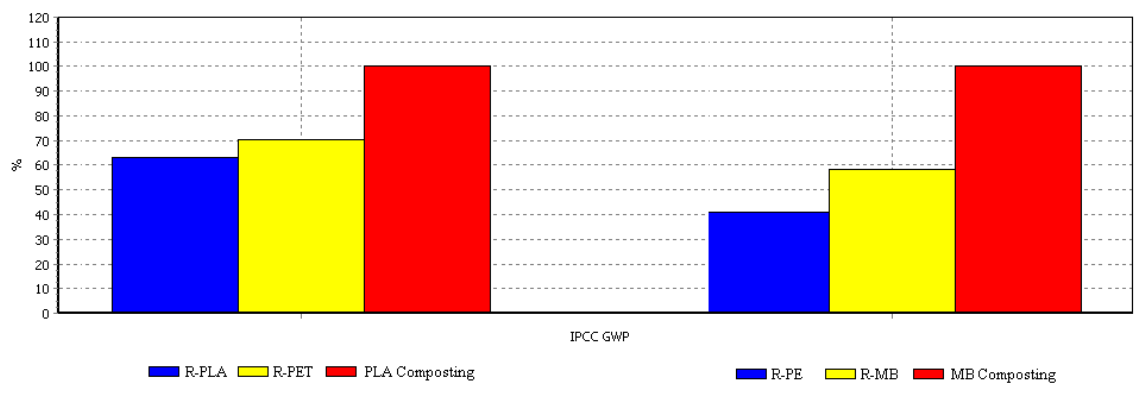

Figure 3: Global Warming Potential of PET/PLA bottles and PE/MB shoppers considering the recycling and the composting processes as waste scenarios.

In order to extend the comparison between petroleum-based plastics and bioplastics to others impact categories, LCAs cradle to grave were carried out by using the Eco-indicator 99 methodology. Figures 4 and 5 report the comparison between R-PET and R-PLA and R-PE with R-MB, respectively. All the comparisons were made at "Damage Categories" level. Figure 4 shows that the R-PLA bottles production has a strong impact in terms of damage to the ecosystem quality (it is worth noting that this macro-category includes the impact categories "acidification", "eutrophication", "ecotoxicity" and "land occupation"). On the contrary, the effects on human health are roughly the same for R-PLA and R-PET. Finally, a greater damage in terms of consumption of non-renewable resources is associated with R-PET bottles production.

On the one hand, PLA allows one to save in terms of fossil resources, on the other, it causes more damage in terms of ecosystem quality. In fact, for the PLA 
production it is necessary to use several chemicals (pesticides, herbicides, fertilizers) that are particularly harmful for the environment.

Again, figure 5 points out that the MB shoppers overweight leads to higher impact score of R-MB shoppers with respect to R-PE shoppers in all the damage categories.

Indeed, for a quantitative and objective comparison between the two products under investigation, on the basis of the three macro-categories of damage, a single overall impact index is needed. To this end we must assign a weight to the individual macro-category and define a global index of impact, $I$, given by:

$$
I=\sum_{i} p_{i} c_{i}
$$

where $p_{i}$ is the assigned weight to the macro-category of damage $i$, and $c_{i}$ is the value of the macro-category of damage. The result in terms of "advantage" (that is a better overall impact score) of R-PET or R-PLA bottles is a function of the importance (i.e. the weight) that will be assigned to individual macro-categories.

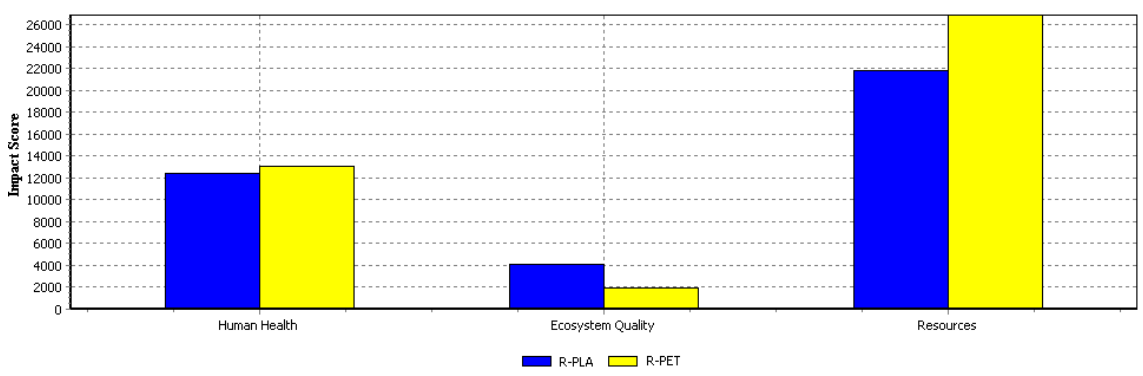

Figure 4: Environmental Impact of R-PET/R-PLA bottles assessed by the Eco-indicator 99 method: damage categories level.

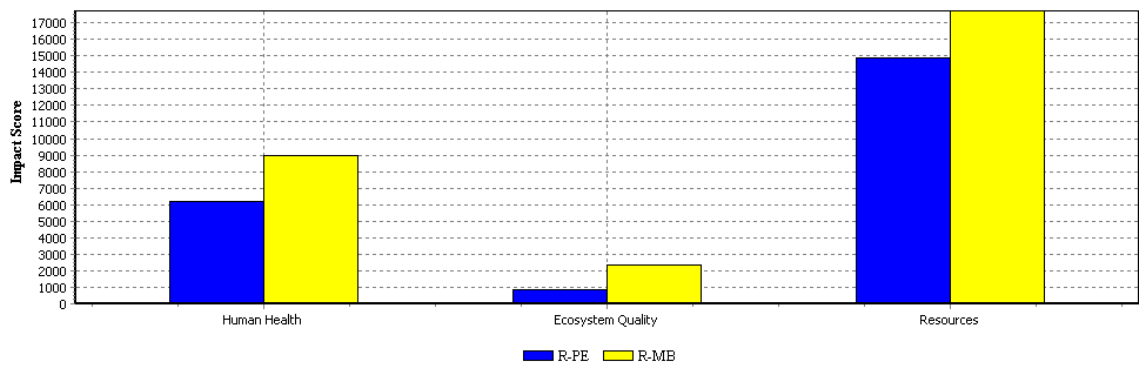

Figure 5: Environmental Impact of R-PE/R-MB shoppers assessed by the Eco-indicator 99 method: damage categories level.

Representing the three categories in a "mixing diagram" (Hofstetter et al. [21]), each point within the triangle represents a weighting combination. In each point of the mixing triangle, the relative weights always add up to $100 \%$. In a mixing triangle, each corner represents a weight of $100 \%$ for one damage 


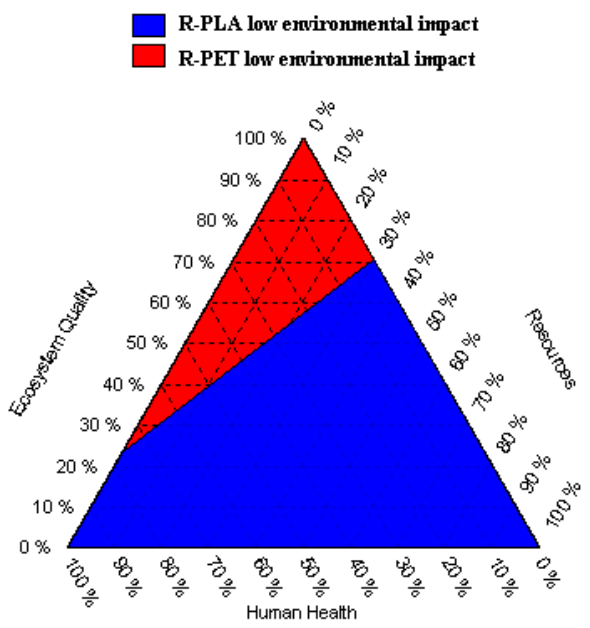

Figure 6: Overall environmental impact of R-PET and R-PLA bottles assessed by the mixing triangle approach.

category; in figure 6, the top corner is the weighting combination where "Ecosystem Quality" is weighted $100 \%$, and $0 \%$ weight is given to both "Human Health" and "Resources." Any point on the base of the triangle of figure 3 gives $0 \%$ weight to "Ecosystem Quality," and the weights are split between " $100 \%$ Human Health / 0\% Resources" in the bottom-left corner to " $0 \%$ Human Health / $100 \%$ Resources" in the bottom-right corner. We only consider positive weights, that is, a positive impact score always means a damage: only points within the mixing triangle are taken as reasonable weighting sets. Therefore, we can evaluate for each set of weights the value of $I$ for the two products tested, in this way we can locate the area of advantage for the R-PET $\left(I_{R-P E T}<I_{R-P L A}\right)$ or for the R-PLA depending on the set of weight

From figure 6 it is evident that R-PET bottles are preferable to R-PLA bottles, from an environmental point o view, only for high values of "ecosystem quality" and "human health" macro-categories, that is only if we assign a low weight to the resources depletion.

\section{Conclusions}

It is commonly believed that the use of renewable materials, such as bio-based plastics, to displace petroleum-based materials, can lead toward a reduction of GHG associated emissions. Actually, the environmental advantage of bioplastics is drastically reduced if the Land Use Change emissions are also taken into account. In order to overcome the LUC problem an effective system would have to guarantee that bioplastics use a feedstock, such as a waste product, or carbonpoor lands that will not trigger large emissions from land-use change. 
The LCA cradle to grave results reported in this paper showed that a smart management of the bioplastic wastes, e.g. mechanical recycling process, can be a valid solution to the LUC problem. In particular the comparison between R-PET and R-PLA bottles highlighted the overall environmental advantage of displacing PET with PLA bottles obtained by mechanical recycling of waste products. As for the Mater-Bi shoppers, no advantages seem to be achievable displacing PE shoppers with MB-shoppers also considering the mechanical recycling as optimal waste management option. Indeed, this results is closely related to the Mater-Bi polymer type considered in this work. Further investigations are needed when literature data will be available on the new Mater-Bi polymer type under development by Novamont.

To conclude, it is worth noting that due to the uncertainties associated with the LCI data reliability and LCA method used, the results reported in this paper can be useful to draw first considerations about the environmental reliability of bioplastics, but cannot be taken as guidelines for the market use of PET or PE rather than PLA bottles or MB shoppers, and vice versa.

\section{Acknowledgement}

The authors thank CONAI for their useful contribution.

\section{References}

[1] Widdecke, H., Otten, H., Marek, A., and Apelt, S. Bioplastics 07/08, Processing Parameters and technical characteristics, a global overview CTC GmbH Fachhochschule Braunschweig/Wolfenbuttel. 2008

[2] Tokiwa Y. and Calabia B.P., Biodegradability and biodegradation of poly(lactide), Applied Microbiology and biotechnology, 72:244-251, 2006.

[3] Bastioli C., Starch-Based Technology, Handbook of Biodegradable Polymers, Rapra technology limited, 8:257-286, 2005.

[4] Zhang, J. Y., Beckman, E. J., Piesco, N. P. and Agarwal, S. A new peptidebased urethane polymer: synthesis, biodegradation, and potential to support cell growth in vitro. Biomaterials 21:1247-1258, 2000.

[5] Demirbas A. Biodegradable plastics from renewable resources. Energy Sources Part A 29:419-424, 2007.

[6] Anderson, J. M., Hiltner, A., Wiggins, M. J., Schuber, M. A., Collier, T. O., Kao, W. J., and Mathur A. B. Recent advances in biomedical polyurethane biostability and biodegradation. Polymer International 46:163-71, 1998.

[7] Gross, R. A., and Kalra, B. Biodegradable polymers for the environment. Green Chem. 297:803-807, 2002.

[8] Harding, K. G., Dennis, J.S., von Blottnitz, H., and Harrison, S.T.L. Environmental Analysis of Plastic Production Processes: Comparing petroleum-based polypropylene and polyethylene with biologically-based poly- $\beta$-hydroxybutyric acid using life cycle assessment, Journal of Biotechnology 130:57-66, 2007. 
[9] Krueger, M., Kauertz, B., and Detzel, A. Life cycle assessment of food packaging made of Ingeo biopolymer and (r)PET, IFEU, Heidelberg, Germany. 2009

[10] Patel, M. Life Cycle Assessment of Synthetic and Biological Polyesters, proceedings of "International symposium on biological polyesters", Munster (Germany). 2002

[11] Searchinger T., Heimlich R., Houghton R.A., Dong F., Elobeid A., Fabiosa J., Tokgoz S., Hayes D., Yu T.H., Use of U.S. Croplands for Biofuels Increases Greenhouse Gases Through Emissions from Land-Use Change, Science 319: 1237-1241, 2008.

[12] Righelato R., Spracklen D.V., Carbon Mitigation by Biofuels or by Saving and Restoring Forests?, Science, 317:902, 2007.

[13] Plevin RJ., Mueller S., The effect of $\mathrm{CO} 2$ regulations on the cost of corn ethanol production, Environmental Research Letters, 3, 1-9, 2008.

[14] Levenmore G.J., A review of the IPCC Assessment Report Four, part 1: the IPCC process and greenhouse gas emission trends from buildings worldwide, Building Services Engineering Research and Technology 29(4):349-361, 2008.

[15] Goedkoop M., Oele M., Schryver M., Vieira M., SimaPro database Manual: Methods Library, PRè Consultants, 22-25, 2008.

[16] Ecoinvent v.2 Report: Overview and Methodology, Frischknocht R. and Jungbluth N. Editors, 2007.

[17] Erwin T.H., Glassner D.A., Kolstad J.J., Wooley R.J., O'Connor R.P., The eco-profiles for current and near-future NatureWorks polylactide (PLA) production, Industrial Biotechnology, 3(1): 58-81, 2007.

[18] Guo L. B., Gifford R. M., Soil carbon stocks and land use change: a metaanalysis, Glob. Change Biol. 8:345, 2002.

[19] Murty D., Kirschbaum M. U. F., McMurtie R. E., McGilvray H., Does conversion of forest to agricultural land change soil carbon and nitrogen? A review of the literature, Glob. Change Biol. 8:105, 2002.

[20] Werner F., Stettler C., Life cycle Inventories of Renewable Materials, Ecoinvent Report n ${ }^{\circ}$ 21, 2007.

[21] Hofstetter P., Braunschweig A., Mettier M., Wenk R.M., Tietje O., The Mixing Triangle: Correlation and Graphical Decision Support for LCAbased Comparison, Journal of Industrial Ecology, 3(4): 97-115, 2008.

[22] Environmental Product Declaration of Mater-Bi NF07U, Novamont, Italy http://bio4eu.jrc.ec.europa.eu/documents/e_epd102.pdf, 2004. 